Viso: Cadernos de estética aplicada

Revista eletrônica de estética

ISSN 1981-4062

$N^{\circ} 29$, jul-dez/2021

http://www.revistaviso.com.br/
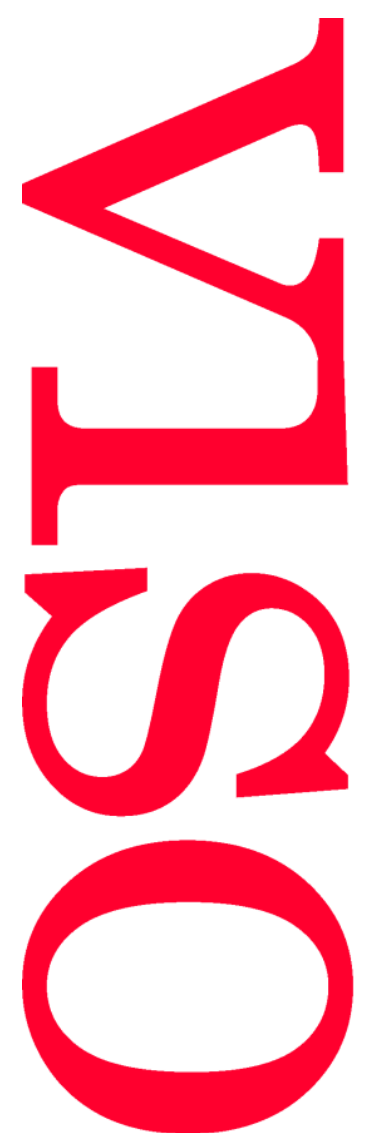

\title{
Por que a espacialidade é mais subversiva do que a temporalidade Bruno Guimarães
}




\section{RESUMO}

Por que a espacialidade é mais subversiva do que a temporalidade

Ao comentar o texto de Miguel Gally sobre as artes espaciais e a politização que se dá através das obras de arte que exploram o espaço, este artigo gostaria de destacar o potencial disruptivo das heterotopias de Michel Foucault. Em favor dos argumentos de Gally demonstrarei como uma conferência de Foucault sobre Outros espaços, de 1967, confirma que a espacialidade é mais subversiva que a temporalidade, mas gostaria também de avaliar os limites dessa tese. Partindo de sua pesquisa sobre as artes espaciais, comentando o modo como a ocupação dos espaços promove a heterotopia social e política, pretendo questionar a exemplaridade paradigmática que a obra Parangolés, de Hélio Oiticica, assume na derrubada de preconceitos sociais, barreiras de grupos e classes. Finalmente, pretendo discutir a ideia de recepção e de comunicação espacial, questionando os limites da própria ideia de comunicação, a partir do papel social que as vanguardas artísticas exercem na sociedade.

Palavras-chave

arte espacial; heterotopia; Foucault; Oiticica; comunicação espacial

\section{ABSTRACT}

\section{Why Is Spatiality More Subversive than Temporality}

By commenting Miguel Gally's text about space arts and the politicization that takes place in artworks that explore space, this article would like to highlight the disruptive potential of Michel Foucault's heterotopias. In favour of Gally's arguments, I will demonstrate how Foucault's 1967 lecture of Other Spaces confirms that spatiality is more subversive than temporality, but I would also like to evaluate the limits of this thesis. Based on his research on space arts, commenting how the occupation of spaces promotes social and political heterotopia, I intend to question the paradigmatic exemplarity that Hélio Oiticica's artwork Parangolés assumes in the overthrow of social prejudices, barriers of groups and classes. Finally, I intend to discuss the idea of reception and spatial communication, questioning the limits of the very idea of communication, based on the social role that artistic avant-garde plays in society.

Keywords

space art; heterotopy; Foucault; Oiticica; spatial communication 


\section{GUIMARÃES, Bruno. "Por que a espacialidade é mais subversiva do que a temporalidade ". Viso: Cadernos de estética aplicada, v. 15, n² 29 (jul-dez/2021), p. 146-}

160.

DOI: $10.22409 / 1981-4062 / v 29 i / 419$

Aprovado: 30.11.2021. Publicado: 30.01.2022.

(c) 2021 Bruno Guimarães. Esse documento é distribuído nos termos da licença Creative Commons Atribuição-NãoComercial 4.0 Internacional (CC-BY-NC), que permite, exceto para fins comerciais, copiar e redistribuir o material em qualquer formato ou meio, bem como remixá-lo, transformá-lo ou criar a partir dele, desde que seja dado o devido crédito e indicada a licença sob a qual ele foi originalmente publicado.

Licença: http://creativecommons.org/licenses/by-nc/4.0/deed.pt_BR

Accepted: 30.11.2021. Published: 30.01.2022.

(C) 2021 Bruno Guimarães. This document is distributed under the terms of a Creative Commons Attribution-NonCommercial 4.0 International license (CC-BY-NC) which allows, except for commercial purposes, to copy and redistribute the material in any medium or format and to remix, transform, and build upon the material, provided the original work is properly cited and states its license.

License: http://creativecommons.org/licenses/by-nc/4.0/ 


\section{Introdução}

0 ponto de partida que mobilizou as observações que se seguem foi um comentário de Gally sobre Danto que aborda a dupla dimensão política do discurso e da experiência - essa dupla dimensão que percorre todo o seu texto (a dimensão teórica e a estética no stricto sensu) - e a ambiguidade que o colega reconhece no seu discurso pluralista. Na perspectiva do filósofo e crítico de arte norte-americano estaria implícita a dimensão política que atribui à arte a liberdade de ser apenas um "discurso incorporado sobre", sem que seja o caso de defender ou criticar uma determinada forma de organização social, podendo o mesmo adotar a forma de uma crítica social ou até de propaganda, ainda que permanecesse em Danto uma certa limitação de visão imposta por sua subordinação a uma certa "política do sensível", conforme a categoria sugerida por Jacques Rancière. Em outras palavras, o próprio pluralismo de Danto estaria restrito às limitações daquilo que o crítico não consegue ver em razão de sua subordinação a uma política do sensível.

A partir do que foi dito, gostaria de sugerir que as principais questões que me proponho a debater estão intimamente conectadas. De início, lembraria que Rancière, no texto $A$ partilha do sensível, afirma que essa política da estética, que define o que é visível ou não em um espaço comum, deveria ser entendida "num sentido kantiano - eventualmente revisitado por Foucault - como o sistema das formas a priori determinando o que se dá a sentir". ${ }^{1}$ Portanto, esse sentido kantiano revisitado por Foucault deveria ser entendido como um a priori histórico, retirando a a-historicidade do transcendental kantiano para formular uma crítica dos sistemas das formas a priori de se sentir em cada momento ou contexto. Mas, seguindo essa intuição, a verdadeira pergunta que gostaria de fazer ao colega Gally, estendendo-a também aos leitores, é se algo que não chega a modificar as formas $a$ priori de nossa sensibilidade é verdadeiramente capaz de produzir uma derrubada de preconceitos sociais e barreiras de grupos e classes. Será mesmo que algo que não chega a 
produzir uma revolução nas raízes que subjazem à nossa forma de conhecer ainda é capaz de produzir uma transcendência dessa partilha política do sensível, no sentido de Rancière?

Tomando um exemplo muito proeminente em vários textos de meu colega ${ }^{2}$, ainda que apareça de modo muito secundário ou apenas implícito neste artigo que ora comento, seria o caso de perguntar se o convite/diálogo que o artista propõe ao coletivo, na obra Parangolés, seria mesmo capaz de promover a derrubada de preconceitos e barreiras sociais, como parecia pretender o próprio Hélio Oiticica; ou se, de um ponto de vista mais pessimista e dialético, o espaço destinado à exploração comercial da arte não permanecia cúmplice da mesma realidade que a obra pretendia questionar. Vale lembrar, por exemplo, que apesar de ter sido pensada para ser apresentada em uma exposição dinâmica em que integrantes da escola de samba da comunidade da Mangueira haveriam de dançar e interagir com as faixas, capas e bandeiras, a Mangueira foi barrada na entrada do MAM, na sua própria exposição de estréia, a Opinião 65 , ocorrida em 1965, obrigando Helio e seus passistas a se exibirem no lado de fora, no jardim. ${ }^{3}$

\section{Sobre a potência disruptiva das heterotopias}

Voltando agora à dupla dimensão política do espaço de que falávamos no início do texto, a teórica e a estética propriamente dita - esta última pensada segundo a origem etimológica da palavra grega aisthésis, que nos remete à experiência e à sensibilidade - não há dúvida de que as duas dimensões estão presentes no pensamento de Foucault. $\mathrm{Na}$ conferência de 1967 mencionada por Gally, Outros espaços, dirigida ao círculo de estudos arquiteturais de Paris, Foucault demonstra como o espaço é visto como posicionamento articulável e crítico frente a outros espaços. Um modelo heterotópico para isso poderia ser extraído do seu comentário sobre o espelho. Segundo Foucault, "acredito que entre as utopias e estes posicionamentos absolutamente outros, as heterotopias, haveria, sem dúvida, uma espécie de experiência 
mista, mediana, que seria o espelho". ${ }^{4}$ Aqui a sugestão é a de que o espelho funcione como uma analogia dessa experiência mista, já que, diferentemente das utopias, que são espaços negativos, ou fundamentalmente irreais, as heterotopias do espelho seriam espécies de contra-lugares, ou lugares utópicos efetivamente realizados em outros espaços, que me "permitem olhar lá onde estou ausente". ${ }^{5}$ Como observa o comentário de Defert sobre o texto no "Posfácio" de O corpo utópico, as heterotopias, essas heterotopias são subversivas porque "estes espaços diferentes são a contestação dos espaços onde vivemos". 6

Mais uma vez, o espelho como espaço real é também analogia de como o lugar onde não estou reflete o contexto onde estou. Mas a heterotopia teria a vantagem de ser um lugar outro, existente, enquanto a utopia seria por definição um não lugar, um lugar sem lugar, um espaço inexistente. Em outro exemplo eloquente de como esses espaços outros nos são essenciais, Foucault conclui o texto nos falando do navio, como um pedaço flutuante de espaço, um lugar não fixo lançado à infinitude do mar, e nos lembra de como as heterotopias desnaturalizam o espaço normativo em que vivemos. Segundo ele, "em civilizações sem barcos, esgotam-se os sonhos, e a aventura é substituída pela espionagem, os piratas pelas polícias". ${ }^{7}$

Voltando ao comentário sobre o texto de Foucault, Daniel Defert, no "Posfácio" de O corpo utópico, as heterotopias, lembra como essa conferência de 1967 teria inspirado um grande número de arquitetos a radicalizar a arquitetura, a analisar as qualidades normativas das estruturas e instituições, inspirando-os a projetar cidades por fragmento e promover uma verdadeira revolução no urbanismo. Defert inclusive relata que, certa vez, Foucault teria manifestado algum desapontamento pelo fato de ter sido esta conferência e não As palavras e as coisas que retivera o olhar do arquiteto para as rupturas do pensamento. ${ }^{8}$ Seu comentário relembra como a esquerda marxista, existencialista e maoísta bombardeara o livro de Foucault, como entendera que ele inviabilizava a 
revolução por não compreender que "o espaço era reacionário e capitalista, enquanto a história e o devir [seriam] revolucionários". ${ }^{9}$ Um caso emblemático ficou registrado no filme de Godard, $A$ chinesa, de 1967, no qual uma estudante pró-chinesa joga tomates em um exemplar de As palavras e as coisas. $^{10}$

Mas Defert lembra também como o livro, lançado na primavera anterior, se abria com a descrição de uma improvável enciclopédia chinesa inventada por Borges, segundo a qual os "animais se distribuíam em quatorze classes do seguinte tipo:
a) pertencentes ao imperador; b) embalsamados; c) domesticados...; k) desenhados com um pincel muito fino de pelo de camelo I) et cetera"; e como justamente "essa desordem que faz cintilar os fragmentos de um grande número de ordens possíveis" já fora batizada, no ano anterior à conferência dos Outros espaços, como uma forma de "heterotopia". ${ }^{11}$

Vale lembrar que, ainda no prefácio de As palavras e as coisas, discutindo por que a estranheza da ordem apresentada por Borges nos faz rir, Foucault menciona a mesa de trabalho com o guarda-chuva e a máquina de costura para nos fazer refletir sobre o espaço implícito dessa ordem. ${ }^{12}$ Ele estaria fazendo alusão a uma frase do escritor uruguaio Isidore Ducasse, também conhecido como o "Conde de Lautréamont", que assinala aquilo que é "belo como o encontro fortuito de uma máquina de costura e um guarda-chuva sobre uma mesa de dissecação"13, imagem essa que seria imortalizada por Salvador Dali em sua obra Máquina de costuras com guardachuva em uma paisagem surrealista, de 1941.

Ao fazer referência a essa obra, Foucault parecia querer remeter nossa atenção a esse projeto surrealista de tornar visível uma realidade inconsciente que antecede e transcende a realidade cotidiana, forçando-nos a entender as coisas de outra maneira. Mais especificamente, em sentido prático ligado ao seu projeto teórico, Foucault gostaria de escavar a ordem inconsciente que rege o saber. Não deveríamos pensar, nesse 
caso, no inconsciente freudiano em sentido substantivo ou sistemático, mas muito mais em uma espécie de condição implícita, ou mesmo em um a priori histórico que decide quais são os objetos que deveriam atuar sobre o mesmo espaço operacional.

Este seria propriamente o sentido do trabalho arqueológico empreendido por Foucault: analisar o princípio de organização do espaço de saber de cada época para tornar possível, por exemplo, o reconhecimento de que o Renascimento era regido pelo princípio da semelhança, o que explicaria por que a magia podia conviver ao lado da erudição e da exegese, e não apesar delas, ou ainda por que se acreditava na época que uma noz deveria ser usada no tratamento das dores de cabeça do cérebro. ${ }^{14}$ Do mesmo modo explicaria como, nos séculos seguintes, sécs. XVII e XVIII, o princípio que passa a reger 0 pensamento é o da representação e por que, sendo a mente basicamente uma atividade de representação, não se poderia representar a mente representando. Aplicada à estética, essa conclusão renderia ao primeiro capítulo de As palavras e as coisas uma brilhante análise sobre a obra de Velázquez, Las meninas $^{15}$, explicando, entre outras coisas, por que o pintor, que aparece atrás da tela como reflexo no espelho, só é visível no momento em que não está pintando. ${ }^{16}$

É por tudo isso, mais uma vez, que a análise arqueológica da espacialidade em Foucault deveria ser reconhecida como mais subversiva que a própria temporalidade, pois seria o caso de perceber, parafraseando Defert, que a própria escavação da "desordem desnaturaliza a própria ordem histórica, fazendo cintilar os fragmentos de um grande número de ordens possíveis". ${ }^{17}$

\section{Deslocamentos espaço-temporais e comunicação espacial}

No final de seus comentários sobre os efeitos da heterotopia de Foucault, Defert relata como a tradução americana da conferência de Outros espaços, lançada em 1986, foi absorvida por movimentos feministas, gays e grupos étnicos e como 
influenciou a literatura e as artes plásticas. ${ }^{18}$ Seria o caso de mencionar especialmente a obra de Felix Gonzalvez-Torres, descrita pela curadora Nancy Spector como "experiência de ambiente heterotópico realizada em Manhattan". A obra consistia na exposição de vinte e quatro painéis publicitários, nas instalações urbanas de Manhattan, de uma imensa foto em preto e branco da intimidade da cama de casal vazia do artista, exposta possivelmente logo após o amor consumado. Além de publicizar o espaço privado, deslocando sua intimidade ao espaço público, o aspecto mais polêmico ligado à obra talvez viesse de uma advertência do artista de que uma decisão de 1986 da Corte Suprema teria decretado que a sodomia seria ainda um crime e autorizava doravante a justiça, em todo Estado, a persegui-la mesmo quando consentida entre adultos. ${ }^{19}$ Mas, segundo Spector, essa articulação entre 0 público e o privado podia portar uma história ainda mais silenciosa: a marca vazia do companheiro do artista, morto de AIDS em meados dos anos de 1980. Seja como for, cumpre introduzir aqui um elemento temporal para complexificar nossas análises. Afinal, não seria o caso de dizer que nossa sensibilidade para o que parece aceitável ou não em relação a tais deslocamentos espaciais é algo que muda de acordo com o momento e o contexto?

Pensando mais uma vez nesse tipo de deslocamento de lugares nas artes plásticas, pergunto se os readymades de Duchamp e, em especial, o ato escandaloso da inscrição rejeitada de sua obra Fonte (uma peça de porcelana para o banheiro, adquirida em loja de material de construção, apresentada à Society of Independent Artists de Nova York, em 1917), não seriam também acompanhados de um questionamento do espaço teórico da ordem? Afinal, não poderíamos dizer que Duchamp teria sido alguém que também realizou implicitamente um trabalho arqueológico para descobrir uma arbitrariedade no que a sociedade até então estava preparada para reconhecer como arte?

É exatamente nesse ponto que, falando sobre Duchamp, gostaria de retomar o tema da comunicação e lembrar um 
comentário de Flusser em $A$ arte: o belo e o agradável (texto, aliás, que foi traduzido e publicado recentemente por nossa colega Rachel Costa, que participou da mesa de debates que gerou a presente publicação). ${ }^{20}$ Nesse opúsculo, Flusser afirmava que "o artista não está interessado na comunicação das experiências privadas: isso seria, aliás, enfadonho. Seu interesse é nos propor formas novas para nossas experiências futuras, e assim enriquecer nossa realidade, (e a sua)". ${ }^{21}$ Ele chega mesmo a sugerir que o problema da comunicação estética estaria na base da diferenciação entre nossa experiência do que é belo e do que é agradável, na medida em que a beleza é um modelo de experiência que difere de todo modelo precedente. A beleza produziria "um aumento do parâmetro do real". $E$, nesse sentido, ela seria terrível $e$ perigosa, pois arriscaria destruir nossos modelos de comportamento, enquanto que viver agradavelmente seria se contentar com os velhos modelos tradicionais da experiência. Segue-se daí a observação de que o desafio de todo artista seria "caminhar pela trilha estreita que separa a banalidade da loucura, a redundância do rú́do". ${ }^{22}$ Finalmente, nesse sentido, 0 problema da comunicação estética seria entender que, se a obra é

muito "tradicional", ela não é "bela", (ela não aumenta o domínio da experiência). E, se ela contém muita informação, (se ela é muito "avantgarde"), ela também não é "bela", (ela não aumenta o domínio da experiência, pois ela não comunica). ${ }^{23}$

Penso que essas observações de Flusser refletem também o próprio comentário de Duchamp sobre 0 ato criador, escrito em 1965, e que talvez essa última conexão nos leve a problematizar um pouco mais a própria ideia de comunicação. Afinal, o que se comunica não pode ser exatamente a intenção do artista, como poderia pensar o Danto de Transfiguração do lugar comum, por exemplo. ${ }^{24}$

No texto de 1965, Duchamp diz que:

0 ato criador não é executado pelo artista sozinho; o público estabelece o contato entre 
a obra de arte e o mundo exterior, decifrando e interpretando suas qualidades intrínsecas e, desta forma, acrescenta sua contribuição ao ato criador. Isto torna-se ainda mais óbvio quando a posteridade dá o seu veredicto final e, às vezes, reabilita artistas esquecidos. ${ }^{25}$

Em relação à ideia de comunicação, cumpre observar, em primeiro lugar, que Duchamp admite certa relatividade que dá uma vivacidade dinâmica ao conteúdo interpretativo das obras de arte. Uma mesma obra pode ter significados diferentes a partir das diferentes recepções ou interações a que está sujeita. Segundo ele, no ato criador o artista passa da intenção à realização por meio de uma cadeia de reações totalmente subjetivas que não podem e também não devem ser totalmente conscientes, pelo menos no plano estético. Na cadeia de reações que acompanhariam o ato criador, seria o caso de se acrescentar a inabilidade do artista em expressar integralmente a sua intenção, pois a diferença entre o que quis realizar e o que na verdade realizou seria o "coeficiente artístico" pessoal contido na sua obra de arte, caracterizado por Duchamp como "uma relação aritmética entre o que permanece inexpresso embora intencionado, e o que é expresso nãointencionalmente". ${ }^{26}$

Nesse sentido, segundo Duchamp, o artista pode proclamar de todos os telhados que é um gênio, mas terá de esperar pelo veredicto do público para que a sua declaração assuma um valor social e para que, finalmente, a posteridade o inclua entre as figuras primordiais da História da Arte. Aqui, o comentário reflete a própria reversão do tempo que Duchamp experimentou em relação à sua arte pois, como sabemos, ele permaneceu incompreendido durante muito tempo, e só a partir de meados do século passado, com os desdobramentos inusitados da arte contemporânea, passou a ser reconhecido como um gênio incontestável. Finalmente, em última análise, Duchamp confirmaria a ideia de que na recepção da arte não teríamos exatamente uma comunicação de conteúdos intencionais, dispensando, portanto, qualquer teoria comunicacional mais precisa ou sistemática. A partir de Duchamp, e concordando com Flusser, penso que os artistas 
de vanguarda são muitas vezes incompreendidos ao proporem uma nova forma de experiência que vem enriquecer a nossa realidade. Eles correm o risco de não ser absolutamente compreendidos e de não conseguir mudar nossa percepção da realidade, ou, ao menos, podem esperar muito tempo para serem absorvidos. Concluo repetindo Duchamp, mais uma vez, "isto torna-se ainda mais óbvio quando a posteridade dá o seu veredicto final e, às vezes, reabilita artistas esquecidos" ${ }^{27}$

\section{Referências bibliográficas}

DANTO, Arthur. A transfiguração do lugar-comum. Tradução de Vera Pereira. São Paulo: Cosac Naify, 2005.

Após o fim da arte: a arte contemporânea e os limites da história. Tradução de Saulo Krieger. São Paulo: OdysseusEdusp, 2006.

DUCHAMP, Marcel. 0 ato criadorDisponível em <https://asno.files.wordpress.com/2009/06/duchamp.pdf>. Acesso em 28/09/2021.

DEFERT, Daniel. "Posfácio". In: FOUCAULT, Michel. O corpo utópico, as heterotopias. Tradução de Salma Tannus Muchail. São Paulo: N-1 Edições, 2013, p. 33-54.

FOUCAULT, Michel. As palavras e as coisas: uma arqueologia das ciências humanas. Tradução de Salma Tannus Muchail. São Paulo: Martins Fontes, 2007.

A arqueologia do saber. Tradução de Luiz Felipe Baeta Neves. Rio de Janeiro: Forense Universitária, 2008.

. "Outros espaço"s. In: Ditos e escritos III. Estética: literatura e pintura, música e cinema. Organização de Manoel Barros da Motta. Tradução de Inês Autran Dourado Barbosa. Rio de Janeiro: Forense Universitária, 2009, p. 411-422.

O corpo utópico, as heterotopias. Tradução de Salma Tannus Muchail. São Paulo: N-1 Edições, 2013. 
FLUSSER, Vilém. "A arte: o belo e o agradável". Tradução de Rachel Costa. In: Artefilosofia, Ouro Preto, v. 6 n. 9 (julho de 2017), p. 9-13. Disponível em $<$ https://periodicos.ufop.br/raf/article/view/593/549>. Acesso em 28/09/2021.

GALLY, Miguel. "A dimensão política da arte: rascunhos sobre um Hélio Oiticica tardio". Rapsódia, n. 12 (2018), p. 203-222. Disponível em $<$ http://www.revistas.usp.br/rapsodia/article/view/153447>. Acesso em 28/09/2021.

"O gênio coletivo visto a partir das artes espaciais". In: SILVA, Cíntia V.; DUARTE, Pedro (orgs.). Estética. São Paulo: ANPOF (Coleção XVII Encontro ANPOF), 2017, p. 232-242.

"A comunicação espacial e sua materialização nas artes visuais brasileiras". Revista Internacional de Cultura Visual, v. 3, n. 2 (2016), p. 153-164.

LAUTRÉAMONT, Conde de. Os Cantos de Maldoror. Poesias. Cartas. Tradução de Cláudio Willer. São Paulo: Iluminuras, 2005.

NAME, Daniela. "Hélio Oiticica, corpo e carnaval". Revista Caju, Rio de Janeiro, 19/02/2021. Disponível em $<$ http://revistacaju.com.br/2021/02/19/helio-oiticica-corpo-ecarnaval/>. Acesso em 28/09/2021

RANCIÈRE, Jacques. A partilha do sensível: estética e política. Tradução de Mônica Costa Netto. São Paulo: Ed. 34, 2009.

SANTOS, Débora. Uma heterotopia da história: espaço e tempo em As palavras e as coisas de Michel Foucault. Dissertação (Mestrado em Filosofia). Programa de Pós-Graduação em Filosofia, Universidade Federal de Minas Gerais-, Belo Horizonte, 2020. Disponível em <http://hdl.handle.net/1843/34713>. Acesso em 28/09/2021. 
Bruno Guimarães é professor do Departamento de Filosofia da UFOP.

${ }^{1}$ RANCIÈRE, 2009, p. 16.

2 Ver, por exemplo, GALLY, 2019, 2017, 2016.

${ }^{3}$ Chamaria atenção, por exemplo, para a observação da curadora e editora da Revista Caju, Daniela Name, sobre este episódio lamentável, "que, aos olhos de hoje, poderia ser lido como preconceito social e racismo". NAME, 2021

${ }^{4}$ FOUCAULT, 2009, p. 415.

${ }^{5}$ FOUCAULT, 2009, p. 415.

${ }^{6}$ DEFERT, 2013, p. 35.

7 FOUCAULT, 2009, p. 422. Em tempo, gostaria de agradecer à minha companheira, Débora Santos, para dizer como compreendi, acompanhando o trabalho que ela defendeu recentemente na UFMG sobre Uma heterotopia da história: espaço e tempo em As palavras e as coisas, que a idéia de heterotopia já antecipava a investigação final de Foucault sobre a História da sexualidade, da ética e da estética da existência. Em sua dissertação, Débora lembrou, por exemplo, como a Arqueologia do saber, escrita três anos depois de As palavras e as coisas para consolidar o método arqueológico e responder às objeções de seus críticos, já anunciava o desejo de Foucault de empreender uma arqueologia da ética. Afinal, o trabalho arqueológico, que revela uma arbitrariedade no que está por trás do espaço de ordenação de determinado saber ou disciplina, seria o ponto de partida para um grande número de ordens possíveis em outros campos além do epistemológico.

${ }^{8}$ DEFERT, 2013, p. 38.

${ }^{9}$ DEFERT, 2013, p. 52.

${ }^{10}$ DEFERT, 2013, p. 40.

${ }^{11}$ DEFERT, 2013, p. 35.

${ }^{12}$ FOUCAULT, 2007, p. xi.

${ }^{13}$ LAUTRÉAMONT, 2005, p. 252.

${ }^{14}$ FOUCAULT, 2007, p. 35.

${ }^{15}$ FOUCAULT, 2007, p. 3-21.

${ }^{16}$ FOUCAULT, 2007, p. 4.

17 DEFERT, 2013, p. 35.

${ }^{18}$ DEFERT, 2013, p. 53-54.

${ }^{19}$ DEFERT, 2013, p. 55.

${ }^{20}$ FLUSSER, 2017. p. 9-13.

${ }^{21}$ FLUSSER, 2017, p. 11.

${ }^{22}$ FLUSSER, 2017, p. 12. 
${ }^{23}$ FLUSSER, 2017, p. 12.

${ }^{24}$ Cf. DANTO, 2005, p. 183 et seq.

${ }^{25}$ DUCHAMP, 2009. p. 2.

${ }^{26}$ DUCHAMP, 2009. p. 2.

${ }^{27}$ DUCHAMP, 2009, p. 2. 